\title{
Enantioselective HF Loss Promoted by Resonant Two-Photon Ionization of Supersonically Expanded (R)-1-Phenyl-2,2,2-trifluoroethanol Clusters ${ }^{\dagger}$
}

\author{
A. Giardini, ${ }^{\ddagger}$ F. Rondino, ${ }^{\S}$ A. Paladini, ${ }^{\ddagger}$ M. Speranza, ${ }^{\S}$ M. Satta, ${ }^{*, l}$ and S. Piccirillo $*, \perp$ \\ CNR-IMIP, Tito Scalo (PZ), Italy, Dipartimento di Chimica e Tecnologie del Farmaco, Università di Roma \\ "La Sapienza", Rome, Italy, CNR-ISC, Rome, Italy, and Dipartimento di Scienze e Tecnologie Chimiche, \\ Università di Roma “Tor Vergata”, Rome, Italy
}

Received: June 5, 2009; Revised Manuscript Received: September 8, 2009

\begin{abstract}
$(R)$-1-Phenyl-2,2,2-trifluoroethanol and its hydrogen bonded adducts with achiral (water, tetrahydrofuran) and chiral solvent molecules $((R)$ - and $(S)$-butan-2-ol, $(R)$ - and $(S)$-3-hydroxy-tetrahydrofuran) have been ionized by resonant two-photon absorption. The presence of photofragments, attributable to the occurrence of a hydrogen fluoride loss reaction, has been interpreted with the aid of theoretical predictions at the DFT level of theory with the inclusion of dispersive terms. The HF elimination process takes place by a mechanism involving the preliminary $\mathrm{C}_{\alpha}-\mathrm{H}$ hydrogen transfer to an hydroxyl oxygen assisted by the solvent molecule which is followed by extrusion of the HF molecule. The calculated energy barriers depend on the type of solvent as well as on its configuration and are consistent with the observed fragmentation ratios.
\end{abstract}

\section{Introduction}

Understanding the remarkable efficiency and selectivity of many biological processes requires careful investigation of the nature of noncovalent interactions involved in the relevant molecule/receptor systems. In this context, precious information on the transfer of chiral information from the molecular to the supramolecular level can be gained by investigating isolated, noncovalently bound adducts of chiral molecules. Spectroscopic and mass spectrometric methodologies, supported by high-level computational approaches, may allow a detailed and systematic investigation of specific intermolecular interactions in chiral host/guest systems as well as of the dynamics of conceivable reactive processes.

Noncovalent diastereomeric clusters can be generated and isolated by supersonic expansion, and their structure and conformational equilibria have been characterized by several spectroscopic methodologies, such as LIF (laser-induced fluorescence), ${ }^{1}$ R2PI (resonant two-photon ionization), ${ }^{2}$ and more recently by FTIR (Fourier transform infrared) ${ }^{3}$ and microwave spectroscopies. ${ }^{4}$

R2PI spectroscopy, coupled with time-of-flight (TOF) mass spectrometry, provides mass-selective electronic spectra and allows the study of ionic clusters as well as the measure of the binding energies and of reaction thresholds of the diastereomeric complexes. We applied this methodology for evaluating the gasphase structure and the energetics of diastereomeric complexes between chiral aromatic alcohols and a variety of chiral solvent molecules. ${ }^{5,6} \mathrm{We}$ have also shown the effects of asymmetric

\footnotetext{
† Part of the "Vincenzo Aquilanti Festschrift".

* Corresponding authors: piccirillo@ fisica.uniroma2.it, Dipartimento di Scienze e Tecnologie Chimiche, Università di Roma "Tor Vergata", Via della Ricerca Scientifica, 00133 Roma, Italy, tel. +39 06 72594400, fax +39 06 72594328; mausat@caspur.it, CNR-ISC, via dei Taurini 19, Rome, Italy, tel. +3906 49913984, fax +390649910324.

$¥$ CNR-IMIP.

${ }^{\S}$ Dipartimento di Chimica e Tecnologie del Farmaco, Università di Roma "La Sapienza".

"CNR-ISC.

${ }^{\perp}$ Dipartimento di Scienze e Tecnologie Chimiche, Università di Roma "Tor Vergata".
}

microsolvation on the energetics and dynamics of side chain $\mathrm{C}_{\alpha}-\mathrm{C}_{\beta}$ photodissociation in aromatic radical ions. ${ }^{7}$ An important aspect of these studies concerns the efficiency of the fragmentation process, which is enhanced when a hydrogen-bond interaction is present between the chromophore and the solvent molecule and which depends on its configuration, and on the specific conformation (i.e., H-bonded structure) of the adduct. Besides proton transfer processes in the diastereomeric complexes of aromatic molecules with amines, ${ }^{8}$ the observation of enantioselective reactions in isolated clusters is to date not so frequent. One of these rare cases is illustrated in this paper which reports on the results of a R2PI spectroscopic study of supersonically expanded complexes of $(R)$-1-phenyl-2,2,2-trifluoroethanol $\left(\mathbf{F E}_{\mathbf{R}}\right)$ with water $(\mathbf{W})$, tetrahydrofuran $(\mathbf{T f}),(R)$ - and $(S)$-2-butanol $\left(\mathbf{B}_{\mathrm{R} / \mathrm{S}}\right)$, and $(R)$ - and $(S)$-3-hydroxytetrahydrofuran $\left(\mathrm{Th}_{\mathrm{R} / \mathrm{S}}\right)$.

\section{Experimental and Theoretical Calculation}

The molecular beam chamber combined with the linear TOF mass spectrometer used in this work has been previously described. ${ }^{9}$ Clusters were generated in a supersonic-jet expansion of a carrier gas (Ar, stagnation pressure from 2 to 4 bar) seeded with the chromophore and the solvent through a pulsed valve (800 $\mu \mathrm{m}$ i.d., aperture time $200 \mu \mathrm{s}$ ). Diastereoisomeric complexes were formed by expansion of mixtures containing a chromophore of defined configuration, either $(R)$-1-phenyl-2,2,2trifluoroethanol $\left(\mathbf{F E}_{\mathbf{R}}\right)$ or $(R)$-2-phenyl-1,1,1-trifluoropropan-2-ol $\left(\mathbf{F P}_{\mathbf{R}}\right)$, with the $R$ or the $S$ enantiomers of a chiral solvent molecule (solv) to yield the corresponding $\left[\mathbf{F E}_{\mathbf{R}} \cdot \boldsymbol{s o l v}_{\mathbf{R}}\right]$ or $\left[\mathbf{F E}_{\mathrm{R}} \cdot \boldsymbol{s o l} v_{\mathrm{S}}\right]$ diastereomeric adducts. The supersonic jet was skimmed before entering the detection chamber. The molecules and clusters were excited and ionized by a Nd:YAG-pumped pulsed dye laser with associated crystals for nonlinear optical conversion. The generated ions were accelerated and extracted into the TOF mass spectrometer and detected by a channeltron. The signal was recorded and averaged by a digital oscilloscope and stored on a PC. The samples were purchased from Aldrich and used without further purification. 

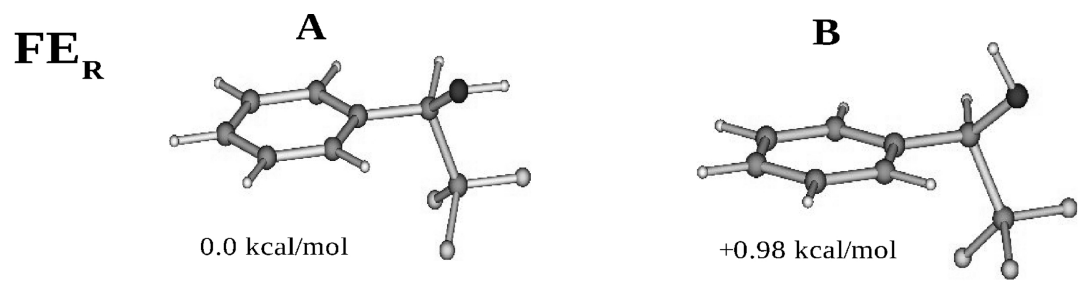

(a)

\section{$\mathrm{FE}_{\mathrm{R}} \mathrm{H}_{2} \mathrm{O}$}
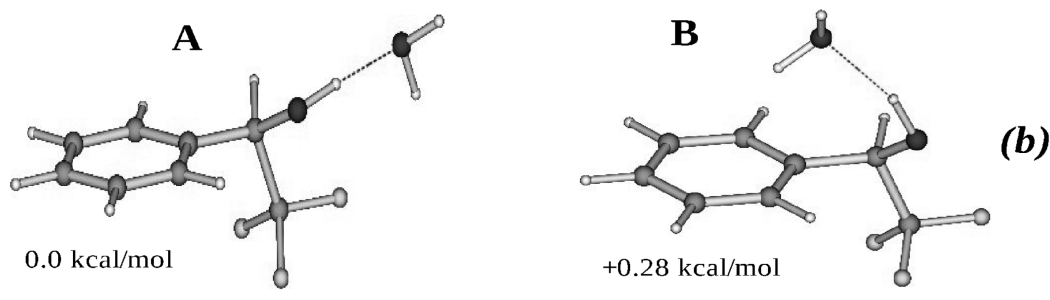

\section{$\mathbf{F E}_{\mathbf{R}} \mathbf{T f}$}
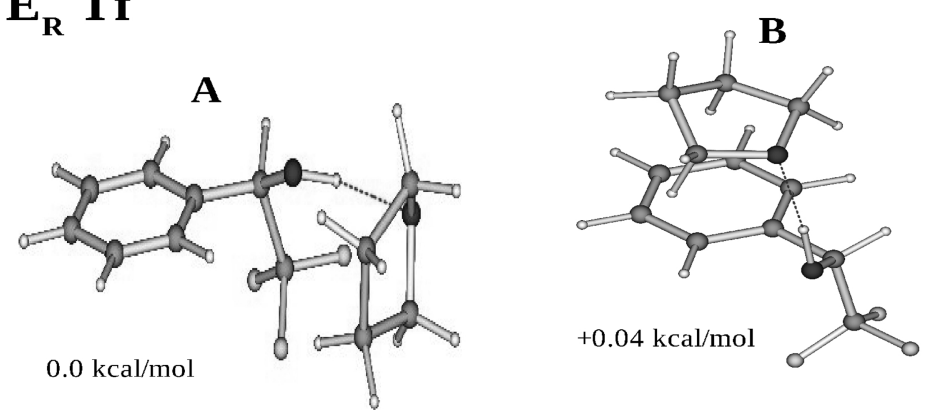

(c)

Figure 1. D-B3LYP/6-31++G** neutral structures and relative energies of (a) $\mathbf{F E}_{\mathbf{R}}$ and (b) $\left[\mathbf{F E} \mathbf{E}_{\mathbf{R}} \cdot \mathbf{W}\right]$ complex. (c) D-B3LYP/6-31G** neutral structures and relative energies of $\left[\mathbf{F E}_{\mathbf{R}} \cdot \mathbf{T f}\right]$ complex.

One color R2PI experiments (1cR2PI) involve electronic excitation of the species of interest by absorption of one photon $h v_{1}$ and by its ionization by a second photon of the same energy $h v_{1}$. The $1 \mathrm{cR} 2 \mathrm{PI}$ excitation spectra were obtained by recording the entire TOF mass spectrum as a function of $v_{1}$.

A preliminary investigation of the conformational landscape of the neutral systems has been conducted by molecular dynamics and mechanics calculation with the MM3 force field. The molecular structures obtained by MM optimization are then reoptimized with density functional theory methodologies. In particular the bare molecule $\mathbf{F E}_{\mathbf{R}}$ and its monohydrated cluster have been studied with B3LYP/6-31G** and D-B3LYP/6$31++\mathrm{G}^{* *}$ level of theory. This last methodology is based on the addition of long-range dispersion contributions to the quantum DFT energy: D-DFT. ${ }^{10}$ In particular, the interatomic dispersion coefficients $\mathrm{C}^{i j}{ }_{6}$ have been estimated as the squared mean of atomic $\mathrm{C}_{6}{ }^{11}$ The overall dispersion term has been increased by a $5 \%$, and the exponential parameter $a$ of the damping function was fixed at a value of 20.0 as suggested by Grimme. ${ }^{12}$ Because of computational limited resources, all the neutral and ionic adducts, but the one with water, have been calculated at the D-B3LYP/6-31G** level of theory. The potential energy curves of the reactive ionic species have been obtained by a full geometry optimization along the scanned variable of interest: e.g., $\mathrm{C}_{\alpha} \mathrm{H} \cdots \mathrm{O}$ and $\mathrm{OH} \cdots \mathrm{F}$ coordinates. The ab initio calculations have been performed with both Gaussian ${ }^{13}$ and NWCHEM ${ }^{14}$ quantum packages.

\section{Results}

3.1. Ground-State Geometries of Neutral and Ion Complexes. The D-B3LYP calculated structures and relative energies of ground-state $\mathbf{F E}_{\mathbf{R}},\left[\mathbf{F E}_{\mathbf{R}} \cdot \mathbf{W}\right],\left[\mathbf{F E}_{\mathbf{R}} \cdot \mathbf{B}_{\mathbf{R} / \mathbf{S}}\right],\left[\mathbf{F E}_{\mathbf{R}} \cdot \mathbf{T f}\right]$, and $\left[\mathbf{F E}_{\mathbf{R}} \cdot \mathbf{T h}_{\mathbf{R} / \mathrm{S}}\right]$ are shown in Figures $1-3$. The D-B3LYP/6$31++\mathrm{G}^{* *}$ structures and relative energies of the most stable conformers of $\mathbf{F E}_{\mathbf{R}}$ are analogous to those obtained with previous calculations performed at MP2/6-31G** level of theory. ${ }^{15}$ The most stable conformer A of $\mathbf{F E}_{\mathbf{R}}$ (Figure 1a) is characterized by the $\mathrm{OH}$ group located out of the plane of the phenyl ring, establishing an intramolecular hydrogen bond with one of the fluorine atoms of the $\mathrm{CF}_{3}$ group. Conformer $\mathrm{B}$ has the hydroxyl hydrogen atom pointing toward the ring plane $\left(\mathrm{OH} \cdots \pi\right.$ bonding). The D-B3LYP/6-31++ $\mathrm{G}^{* *}$ structures of the most stable conformers of $\left[\mathbf{F E}_{\mathbf{R}} \cdot \mathbf{W}\right]$ cluster (Figure 1b) are similar to those previously calculated at the B3LYP/6-31G** level of theory. ${ }^{15}$ In the most stable conformer A, the water molecule acts as a proton acceptor from the $\mathbf{O H}$ group of the chromophore and as a proton donor toward the $\mathrm{F}$ atom anti to the aromatic ring. In conformer B, the water molecule acts as a proton acceptor from the $\mathbf{O H}$ group of the chromophore and as a proton donor toward its $\pi$ ring. The calculated total dispersion term is $1.24 \mathrm{kcal} / \mathrm{mol}$ higher in the less stable conformer B. As a consequence, the predicted relative energy, $+0.28 \mathrm{kcal} / \mathrm{mol}$, is much less than that arising from previous calculations $(1.34 \mathrm{kcal} / \mathrm{mol})^{15}$ where the dispersion term was neglected. Hence, as expected, the inclusion of dispersion terms 


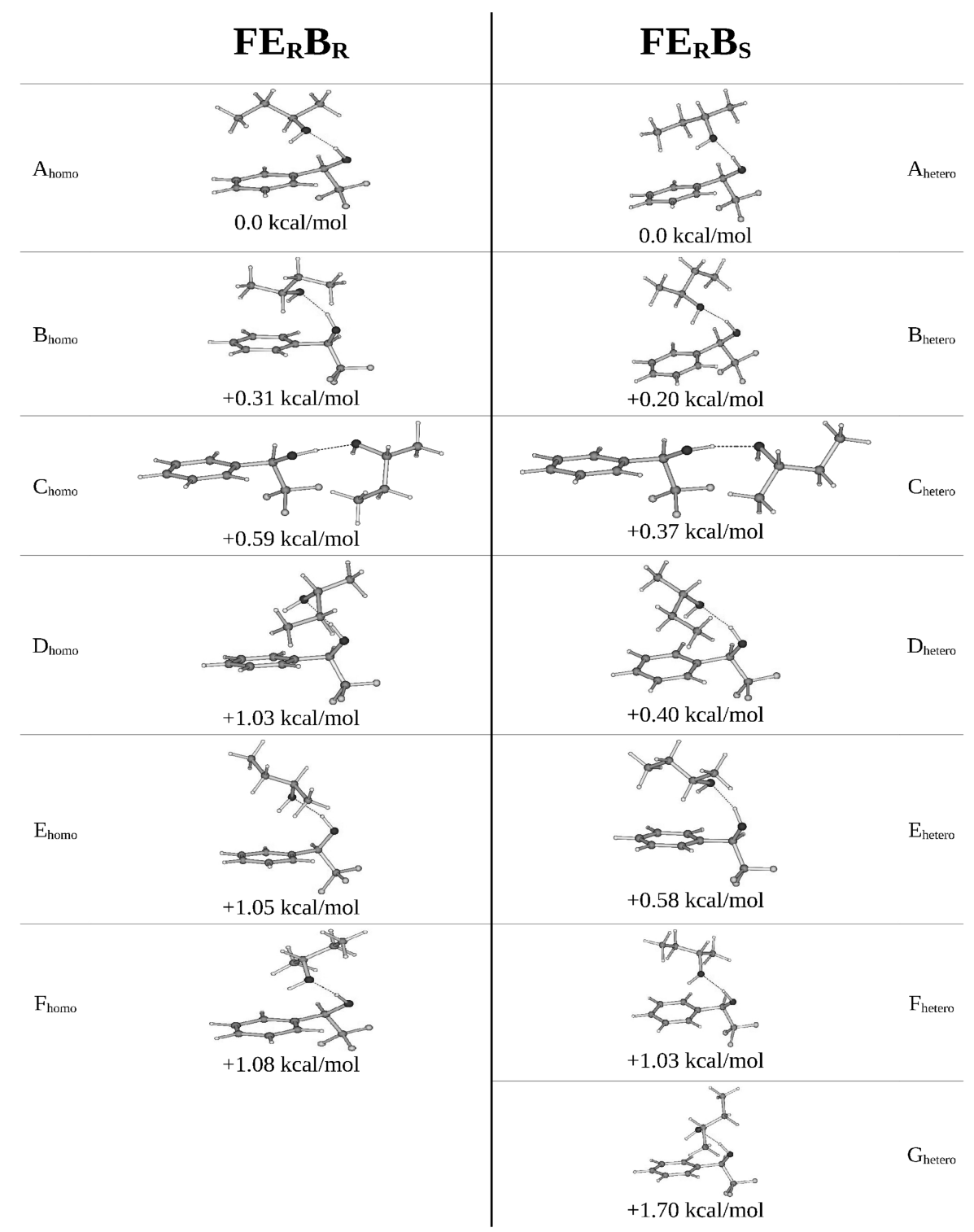

Figure 2. D-B3LYP/6-31G** ground state neutral structures and relative energies of the $\left[\mathbf{F E}_{\mathbf{R}} \cdot \mathbf{B}_{\mathrm{R} / \mathrm{s}}\right]$ complexes.

does not affect appreciably the relative energies of the conformers of bare $\mathbf{F E}_{\mathbf{R}}$, but it has a major impact on the energetics of the conformers of its monohydrated cluster.

Six optimized structures have been identified for $\left[\mathbf{F E}_{\mathbf{R}} \cdot \mathbf{B}_{\mathbf{R}}\right]$ and seven for $\left[\mathbf{F E}_{\mathbf{R}} \cdot \mathbf{B}_{\mathbf{S}}\right]$ with energy differences not exceeding $1.70 \mathrm{kcal} \mathrm{mol}^{-1}$ for $\left[\mathbf{F E}_{\mathbf{R}} \cdot \mathbf{B}_{\mathbf{S}}\right]$ and $1.08 \mathrm{kcal} \mathrm{mol}^{-1}$ for $\left[\mathbf{F E}_{\mathbf{R}} \cdot \mathbf{B}_{\mathbf{R}}\right]$ (Figure 2). In all these structures, the solvent molecule acts as proton acceptor from the $\mathrm{OH}$ group of the chromophore. The most stable structure of each diastereomer $\left(\mathrm{A}_{\text {homo }}, \mathrm{A}_{\text {hetero }}\right)$ has the hydroxyl hydrogen atom of the solvent pointing toward the ring plane $\left(\mathrm{O}^{\text {solv }} \mathrm{H} \cdots \pi\right.$ bonding $)$. Previous B3LYP/6-31G calculations ${ }^{16}$ predicted structures $\mathrm{C}_{\text {homo }}$ and $\mathrm{C}_{\text {hetero }}$ as the most stable ones, characterized by $\mathrm{O}^{\text {solv }} \mathrm{H} \cdots \mathrm{F}$ interactions and by the fact that the alkyl groups are oriented away from to the aromatic ring. The magnitude of the dispersive contribution is lower by about $4-5 \mathrm{kcal} / \mathrm{mol}$ in structures $\mathrm{C}_{\text {homo }}$ and $\mathrm{C}_{\text {hetero }}$ with respect to $A_{\text {homo }}$ and $A_{\text {hetero }}$ and their relative energy results 0.37 and $0.59 \mathrm{kcal} / \mathrm{mol}$ higher at the D-B3LYP/6-31G** level.

Two quasi-isoenergetic conformers have been predicted for the $\left[\mathbf{F E}_{\mathbf{R}} \cdot \mathbf{T f}\right]$ adduct (Figure 1c), both characterized by $\mathrm{OH} \cdot \cdots \mathrm{O}^{\text {solv }}$ interactions. In conformer $\mathrm{A}$, the ring of $\mathbf{T f}$ interacts with the $\mathrm{CF}_{3}$ group, while it interacts with the aromatic ring of the chromophore in conformer B.
Four optimized structures have been identified for the groundstate $\left[\mathbf{F E}_{\mathbf{R}} \cdot \mathbf{T h}_{\mathbf{R}}\right]$ complex and three for its $\left[\mathbf{F E} \mathbf{E}_{\mathbf{R}} \cdot \mathbf{T h}_{\mathbf{S}}\right]$ diastereomer. The most stable $\mathbf{A}_{\text {homo }}$ and $\mathbf{A}_{\text {hetero }}$ structures present two strong hydrogen bonds, one between the hydroxyl group of $\mathbf{F E}_{\mathbf{R}}$ and the ethereal oxygen of $\mathbf{T} \mathbf{h}_{\mathbf{R} / \mathbf{S}}\left(\mathrm{O}^{\mathrm{et}}\right)$, and the other between the hydroxyl group of $\mathbf{T h}_{\mathbf{R} / \mathbf{S}}\left(\mathrm{O}^{\text {al }}-\mathrm{H}\right)$ and the oxygen atom of the chromophore $\left(\mathrm{O}^{\mathrm{chr}}\right)$. These structures have been classified as "insertion" complexes ${ }^{17}$ since the $\mathrm{O}^{\text {chr }} \mathrm{H}$ group is inserted into the intramolecular hydrogen bond of $\mathbf{T h}_{\mathbf{R} / \mathbf{S}}$, and acts either as the $\mathrm{H}$-donor to the most basic site of $\mathbf{T h}_{\mathbf{R} / \mathbf{S}}$ (the $\mathrm{O}^{\text {et }}$ atom) or as the $\mathrm{H}$-bond acceptor from its $\mathrm{O}^{\mathrm{al}}-\mathrm{H}$ alcoholic function. The "addition-type" structures (B,C,D) homo and (B,C) hetero exhibit an $\mathrm{O}^{\text {chr }}-\mathrm{H} \cdots \mathrm{O}^{\text {et }}$ or $\mathrm{O}^{\text {chr }}-\mathrm{H} \cdots \mathrm{O}^{\text {al }}$ hydrogen bond and weaker $\mathrm{O}^{\mathrm{al}}-\mathrm{H} \cdots \mathrm{F}$ or $\mathrm{O}^{\mathrm{al}}-\mathrm{H} \cdots \pi$ interactions.

Figure 4 reports the structures of the most stable conformers of the ionic clusters. The structure of the $\left[\mathbf{F E}_{\mathbf{R}}\right]^{+}$cation resembles that of the lowest-energy neutral conformer (Figure 1a), characterized by the $\mathrm{OH}$ group located out of the plane of the phenyl ring and establishing an intramolecular hydrogen bond with one of the fluorine atoms of the $\mathrm{CF}_{3}$ group. The structure of the $\left[\mathbf{F E}_{\mathbf{R}} \cdot \mathbf{W}\right]^{+}$cation is similar to that of the ground neutral state as well. The most stable $\left[\mathbf{F E}_{\mathbf{R}} \cdot \mathbf{B}_{\mathbf{R} / \mathbf{S}}\right]^{+}$conformers show structures which do not resemble their neutral counterparts 


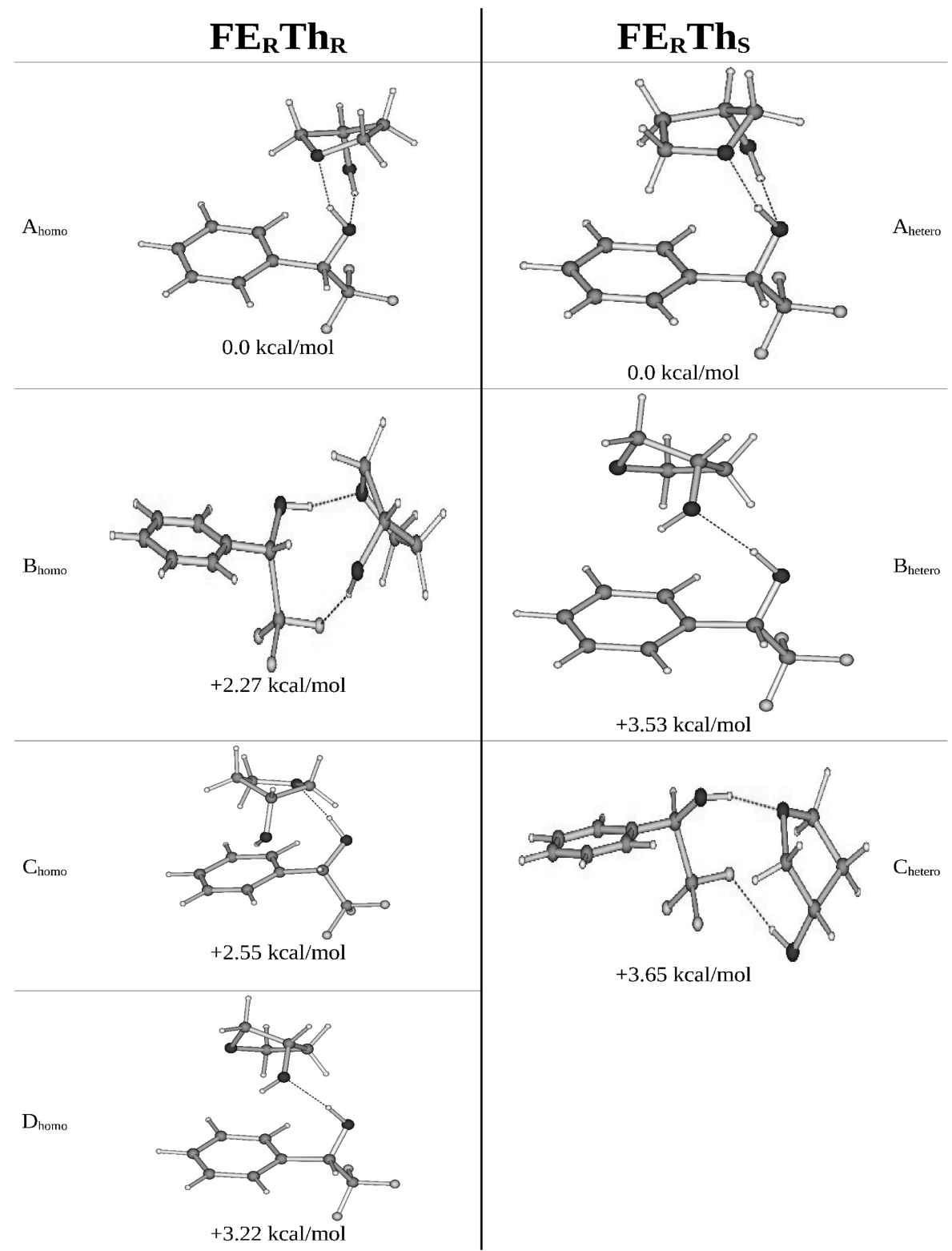

Figure 3. D-B3LYP/6-31G** ground state neutral structures and relative energies of the $\left[\mathbf{F E}_{\mathbf{R}} \cdot \mathbf{T h}_{\mathbf{R} / \mathbf{s}}\right]$ complexes.

( $\mathrm{A}_{\text {homo }}$ and $\mathrm{A}_{\text {hetero }}$ in Figure 2 ), but rather those of the higherenergy neutral forms $\mathrm{C}_{\text {homo }}$ and $\mathrm{C}_{\text {hetero }}$ with the solvent molecule located out of the plane of the aromatic ring (Figure 2). These conformational changes are attributed to the $\mathrm{OH} \cdots \pi$ interaction which becomes repulsive in the cation. It has to be noted that the homochiral $\left[\mathbf{F E}_{\mathbf{R}} \cdot \mathbf{B}_{\mathbf{R}}\right]^{+}$cluster presents a larger dispersive energy contribution $(\sim 2 \mathrm{kcal} / \mathrm{mol})$ with respect to the heterochiral $\left[\mathbf{F E}_{\mathbf{R}} \cdot \mathbf{B}_{\mathbf{S}}\right]^{+}$one. This difference is due to the larger dispersive interactions between the $\mathrm{CF}_{3}$ group of $\mathbf{F E}_{\mathbf{R}}$ and the alkyl chain of 2-butanol in the homochiral adduct than in the heterochiral one (Figure 4).

The structure of the $\left[\mathbf{F E}_{\mathbf{R}} \cdot \mathbf{T f}\right]^{+}$adduct resembles that of the most stable neutral conformer A (Figure 1c) with the chromophore as proton donor toward the oxygen atom of $\mathbf{T f}$ and the ring of $\mathbf{T f}$ located away from the aromatic ring of $\mathbf{F E}_{\mathbf{R}}$. In contrast, the structures of the $\left[\mathbf{F E} \mathbf{E}_{\mathbf{R}} \cdot \mathbf{T h}_{\mathbf{R} / \mathbf{S}}\right]^{+}$conformers differ from those of their most stable neutral counterparts. Rather, they are more similar to those of $B_{\text {homo }}$ and $C_{\text {hetero }}$ (Figure 3 ) wherein the $\mathrm{O}^{\mathrm{al}}-\mathrm{H} \cdots \mathrm{F}$ interactions push the solvent molecule away from the aromatic ring of the chromophore ("addiction" complexes). These ionic conformers are characterized by an additional weak interaction between $\mathrm{C}_{\alpha}-\mathrm{H}$ of $\mathbf{F E}_{\mathbf{R}}$ and $\mathrm{O}^{\mathrm{al}}$ of $\mathbf{T} \mathbf{h}_{\mathbf{R} / \mathbf{S}}($ Figure 4$)$.
3.2. 1cR2PI Spectroscopy of Neutral Complexes. The 1cR2PI excitation spectra of $\mathbf{F E}_{\mathbf{R}},\left[\mathbf{F E}_{\mathbf{R}} \cdot \mathbf{W}\right]$, and $\left[\mathbf{F E} \mathbf{E}_{\mathbf{R}} \cdot \mathbf{B}_{\mathbf{R} / \mathbf{S}}\right]$, have been previously reported. ${ }^{15,16}$ Those of the homochiral $\left[\mathbf{F E}_{\mathbf{R}} \cdot \mathbf{B}_{\mathbf{R}}\right]$ and the heterochiral $\left[\mathbf{F E}_{\mathbf{R}} \cdot \mathbf{B}_{\mathbf{S}}\right]$ complexes are reproduced in Figure 5. The spectra have been taken at the mass of the $1: 1$ cluster, $\mathrm{m} / \mathrm{z}=250$. Similar spectra have been recorded at $m / z=230$, corresponding to the $\left[\mathrm{PhCOHCF}_{2} \cdot \mathbf{B}_{\mathrm{R} / \mathrm{S}}\right]^{+}$fragment. The spectrum of the homochiral $\left[\mathbf{F E}_{\mathbf{R}} \cdot \mathbf{B}_{\mathbf{R}}\right]$ complex is characterized by a very intense band at $37726 \mathrm{~cm}^{-1}$ accompanied by less intense red- and blue-shifted bands falling within the 37685-37710 and 37763-37787 $\mathrm{cm}^{-1}$ intervals (Figure 5a). The spectrum of the heterochiral $\left[\mathbf{F E}_{\mathbf{R}} \cdot \mathbf{B}_{\mathbf{S}}\right]$ complex exhibits a very intense signal at $37790 \mathrm{~cm}^{-1}$ and weaker red-shifted bands in the range $37630-37750 \mathrm{~cm}^{-1}$ (Figure 5b).

On the basis of D-B3LYP/6-31G** predictions, the most populated conformers of $\left[\mathbf{F E}_{\mathbf{R}} \cdot \mathbf{B}_{\mathbf{R}}\right]$ and $\left[\mathbf{F E}_{\mathbf{R}} \cdot \mathbf{B}_{\mathbf{S}}\right]$ should be $A_{\text {homo }}$ and $A_{\text {hetero }}$ (Figure 2). Accordingly, one is inclined to assign the most intense bands in the $\left[\mathbf{F E}_{\mathbf{R}} \cdot \mathbf{B}_{\mathbf{R}}\right]$ and $\left[\mathbf{F E}_{\mathbf{R}} \cdot \mathbf{B}_{\mathbf{S}}\right]$ spectra, located respectively at -56 and $+8 \mathrm{~cm}^{-1}$ from the origin of the bare chromophore, to the $0_{0}{ }^{0}$ electronic $S_{1} \leftarrow S_{0}$ transition of conformers $\mathrm{A}_{\text {homo }}$ and $\mathrm{A}_{\text {hetero }}$, respectively. 


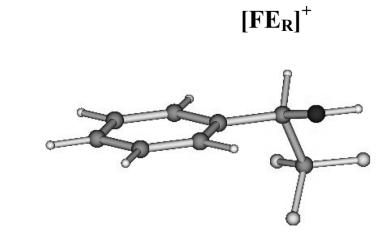

$\left[\mathrm{FE}_{\mathbf{R}} \bullet \mathbf{B}_{\mathbf{R}}\right]^{+}$

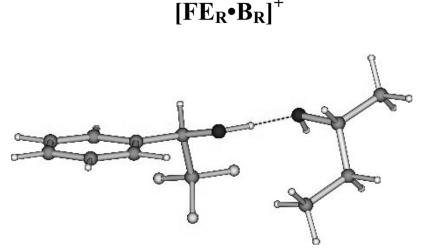

$\left[\mathrm{FE}_{\mathrm{R}} \cdot \mathbf{T f}\right]^{+}$

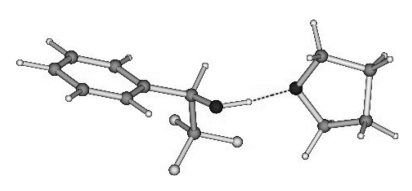

$\left[\mathrm{FE}_{\mathbf{R}} \cdot \mathbf{T h} \mathbf{h}_{\mathbf{R}}\right]^{+}$
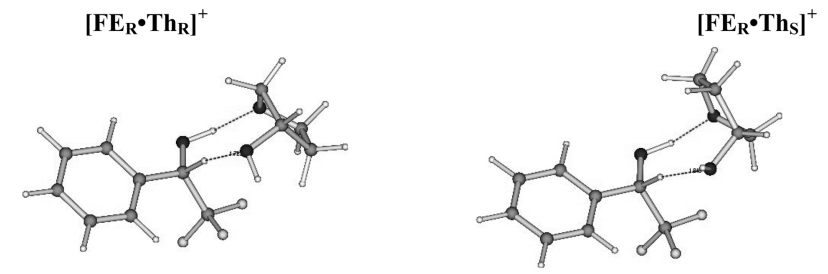

Figure 4. D-B3LYP/6-31G** most stable ion structures.
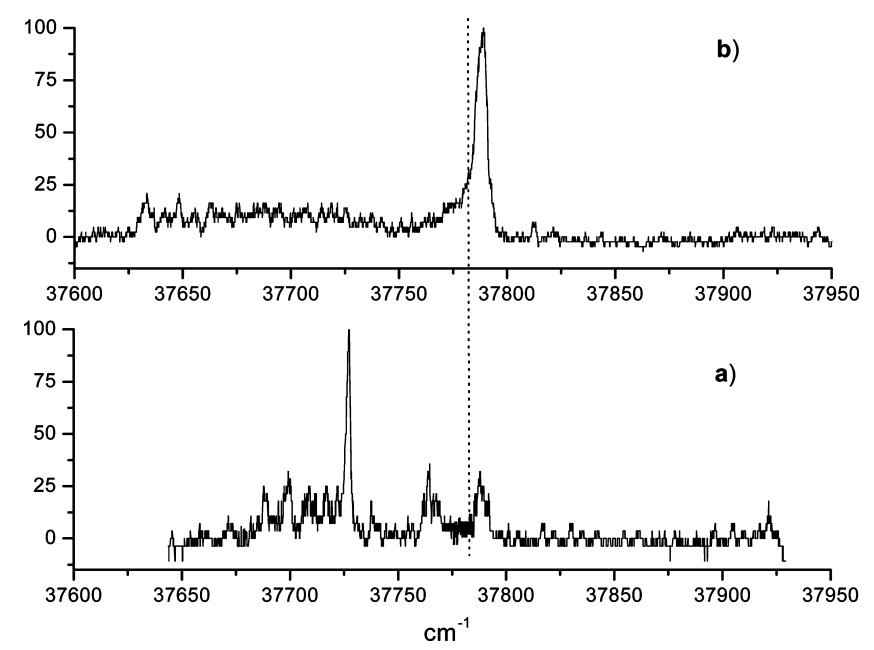

Figure 5. 1cR2PI excitation spectra of the homochiral $\left[\mathrm{FE}_{\mathrm{R}} \cdot \mathrm{B}_{\mathrm{R}}\right]$ complex (a) and the heterochiral $\left[\mathrm{FE}_{\mathrm{R}} \cdot \mathrm{B}_{\mathrm{S}}\right]$ complex (b), recorded at the mass of the cluster $(m / e=250)$. The $0_{0}{ }^{0}$ of bare chromophore $\mathrm{FE}_{\mathrm{R}}$ at $37782 \mathrm{~cm}^{-1}$ is marked as dashed line.

This assignment is acceptable for the homochiral $\left[\mathbf{F E}_{\mathbf{R}} \cdot \mathbf{B}_{\mathbf{R}}\right]$ complex. The red shift of its $0_{0}{ }^{0}$ electronic $S_{1} \leftarrow S_{0}$ transition finds strong analogies with the red shifts previously observed for similar complexes with nonfluorinated chromophores. ${ }^{5-8}$ In these studies, the red shift was associated to the chromophore acting as the proton donor and to the contribution of dispersive interactions between the aliphatic chain of the alcohol and the $\pi$-system of the chromophore. Thus, the band at $37726 \mathrm{~cm}^{-1}$ $\left(\Delta v=-56 \mathrm{~cm}^{-1}\right)$ in the spectrum of $\left[\mathbf{F E}_{\mathbf{R}} \cdot \mathbf{B}_{\mathbf{R}}\right]$ can be attributed to the most stable calculated structure $A_{\text {homo }}$, while the weaker bands present in the spectrum can be tentatively assigned to the less populated conformers $B_{\text {homo }}$ and $C_{\text {homo }}$. In contrast, the most intense band in the spectrum of $\left[\mathbf{F E}_{\mathbf{R}} \cdot \mathbf{B}_{\mathbf{S}}\right]$ is slightly blueshifted with respect to the $0_{0}{ }^{0} \mathrm{~S}_{1} \leftarrow \mathrm{S}_{0}$ electronic transition of

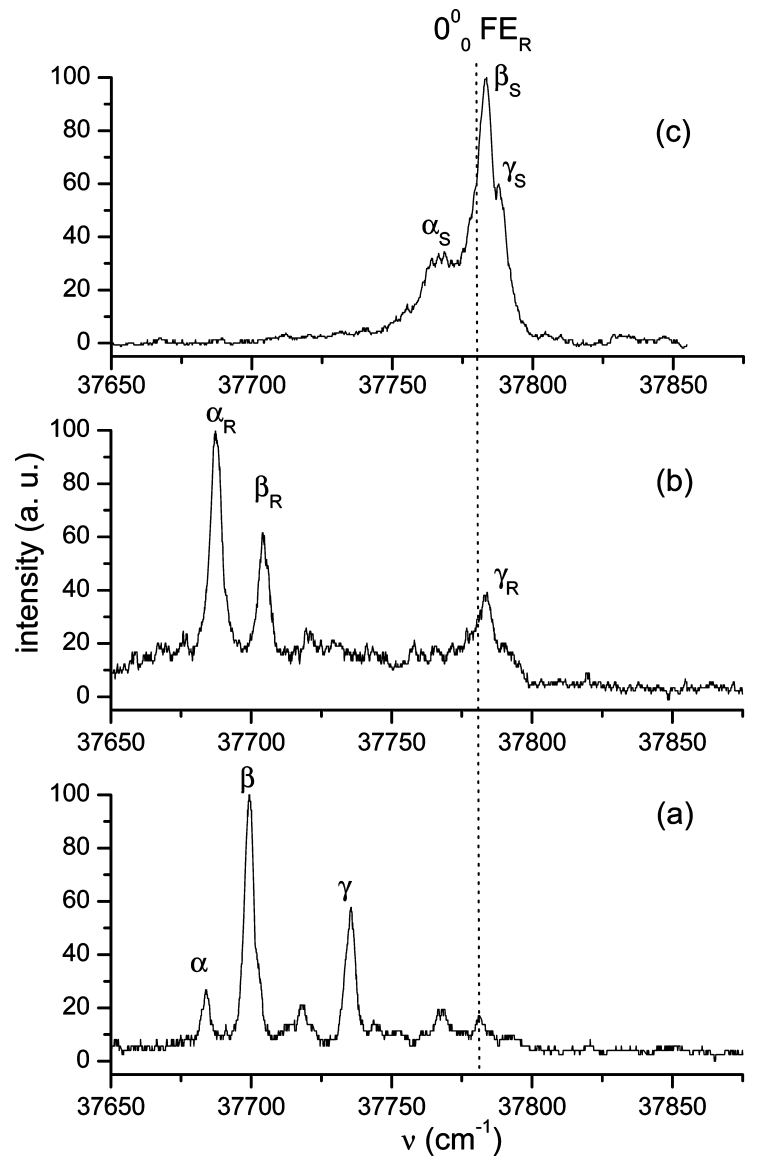

Figure 6. 1cR2PI excitation spectra of $\left[\mathbf{F E}_{\mathbf{R}} \cdot \mathbf{T f}\right](\mathrm{a}),\left[\mathbf{F E}_{\mathbf{R}} \cdot \mathbf{T h}_{\mathbf{R}}\right]$ (b) and $\left[\mathbf{F E}_{\mathbf{R}} \cdot \mathbf{T h}_{\mathbf{S}}\right]$ (c) complexes, recorded at the mass of the $\left[\mathrm{PhCOHCF}_{2} \bullet \mathrm{Tf}\right]^{+}$and $\left[\mathrm{PhCOHCF}_{2} \bullet \mathrm{Th}_{\mathrm{R} / \mathrm{S}}\right]^{+}$fragments $(m / e=228$ and $m / e=244$, respectively). The $0_{0}{ }^{0}$ of bare chromophore $\mathbf{F E}_{\mathbf{R}}$ at $37782 \mathrm{~cm}^{-1}$ is marked as a dashed line.

the bare chromophore. This band can hardly be assigned to the $\mathrm{A}_{\text {hetero }}$ structure, since structures $\mathrm{A}_{\text {homo }}$ and $\mathrm{A}_{\text {hetero }}$ are similar and the contribution of dispersive interactions is comparable. The small spectral shift of this band suggests that the $\pi$ electron densities of the ground and excited states of $\mathbf{F E}_{\mathbf{R}}$ are slightly perturbed by the presence of the $\mathbf{B}_{\mathbf{S}}$ molecule. In this case, structure $\mathrm{C}_{\text {hetero }}$ (Figure 3), which presents negligible interactions between the $\mathbf{F E}_{\mathbf{R}}$ aromatic ring and the solvent molecule, is more consistent with the small blue spectral shift.

The 1cR2PI spectra of $\left[\mathbf{F E}_{\mathbf{R}} \cdot \mathbf{T f}\right]$ and $\left[\mathbf{F E}_{\mathbf{R}} \cdot \mathbf{T h}_{\mathbf{R} / \mathbf{s}}\right]$ complexes are shown in Figure 6. Owing to the large ionic fragmentation ratio of these species, the three spectra were recorded by monitoring the mass of the $\left[\mathrm{PhCOHCF}_{2} \cdot \text { solv }\right]^{+}$fragment channel, corresponding to $\mathrm{HF}$ elimination $(\mathrm{m} / \mathrm{z}=228$ for $\left[\mathbf{F E}_{\mathbf{R}} \cdot \mathbf{T f}\right]$ and $m / z=244$ for $\left.\left[\mathbf{F E}_{\mathbf{R}} \cdot \mathbf{T h}_{\mathbf{R} / \mathbf{S}}\right]\right)$. The spectra are characterized by the presence of triplets of bands. Assignment of these bands to the isomeric structures shown in Figures 1 and 3 is not straightforward. At present, it is only possible to suggest, in analogy with previous experimental evidence for similar systems, ${ }^{17}$ that these bands correspond to the $0_{0}{ }^{0} \mathrm{~S}_{1} \leftarrow$ $\mathrm{S}_{0}$ transitions of different conformers and not to vibronic transitions of a single conformer.

3.3. Mass Spectra. The 1cR2PI-TOF mass spectrum of $\mathbf{F E}_{\mathbf{R}}$, taken in correspondence of its $0_{0}{ }^{0} \mathrm{~S}_{1} \leftarrow \mathrm{S}_{0}$ electronic transitions, does not show any photoinduced fragmentation. That of $\left[\mathbf{F E}_{\mathbf{R}} \cdot \mathbf{W}\right]$, taken at $37792 \mathrm{~cm}^{-1}$, exhibits very weak signals at $m / z=176\left(\left[\mathbf{F E}_{\mathbf{R}}\right]^{+}\right)$arising from the $\mathrm{H}_{2} \mathrm{O}$ loss. The $1 \mathrm{cR} 2 \mathrm{PI}-$ TOF mass spectra of the $\left[\mathbf{F E}_{\mathbf{R}} \cdot \operatorname{sol} v\right]\left(\right.$ solv $=\mathbf{B}_{\mathbf{R} / \mathbf{S}}, \mathbf{T h}_{\mathbf{R} / \mathbf{S}}$, and 
TABLE 1: Fragmentation Ratios of the Chromophore and the Diastereomeric Complexes

\begin{tabular}{lcc}
\hline \multicolumn{1}{c}{ system } & $\begin{array}{c}\mathrm{S}_{1} \leftarrow \mathrm{S}_{0} \\
\text { transition }\left(\mathrm{cm}^{-1}\right)\end{array}$ & $I\left[\mathrm{PhCOHCF}_{2} \cdot \mathbf{s o l v}\right]^{+} / I\left[\mathbf{F E} \mathbf{E}_{\mathbf{R}} \cdot \mathbf{s o l v}\right]^{+}$ \\
\hline $\mathbf{F E}_{\mathbf{R}}$ & 37782 & $<0.005$ \\
$\mathbf{F E}_{\mathbf{R}} \mathbf{H}_{\mathbf{2}} \mathbf{O}$ & 37792 & $<0.005$ \\
$\mathbf{F E}_{\mathbf{R}} \mathbf{B}_{\mathbf{R}}$ & 37726 & 0.51 \\
$\mathbf{F E}_{\mathbf{R}} \mathbf{B}_{\mathbf{S}}$ & 37790 & 0.36 \\
$\mathbf{F E}_{\mathbf{R}} \mathbf{T f}$ & $37699(\alpha)$ & 9.1 \\
& $37734(\beta)$ & 8.3 \\
$\mathbf{F E}_{\mathbf{R}} \mathbf{T h}_{\mathbf{R}}$ & $37687\left(\alpha_{\mathrm{R}}\right)$ & 12.5 \\
& $37704\left(\beta_{\mathrm{R}}\right)$ & 8.3 \\
& $37783\left(\gamma_{\mathrm{R}}\right)$ & $>20$ \\
$\mathbf{F E}_{\mathbf{R}} \mathbf{T h}_{\mathbf{S}}$ & $37764\left(\alpha_{\mathrm{S}}\right)$ & 2.8 \\
& $37783\left(\beta_{\mathrm{S}}\right)$ & 6.7 \\
& $37788\left(\gamma_{\mathrm{S}}\right)$ & 7.7
\end{tabular}

Tf) clusters, taken at the corresponding $\mathrm{S}_{1} \leftarrow \mathrm{S}_{0}$ electronic transitions wavelengths, exclusively yield significant amounts of the $\left[\mathrm{PhCOHCF}_{2} \cdot s o l v\right]^{+}$fragment arising from the $\mathrm{HF}$ elimination. The extent of HF loss is represented in Table 1 by the photofragmentation ratios which are the abundance of the $\left[\mathrm{PhCOHCF}_{2} \cdot s o l v\right]^{+}$fragments relative to that of their $\left[\mathrm{FE}_{\mathbf{R}} \cdot \boldsymbol{s o l v}\right]^{+}$parents.

The different photofragmentation ratios of $\left[\mathbf{F E}_{\mathbf{R}} \cdot s o l v\right]$ (solv $=\mathbf{T h}_{\mathbf{R} / \mathrm{S}}$ and $\mathbf{T f}$ ), taken at the relevant $\alpha, \beta$, and $\gamma$ bands (Figure 6 ), support the assignment of the same bands to distinct
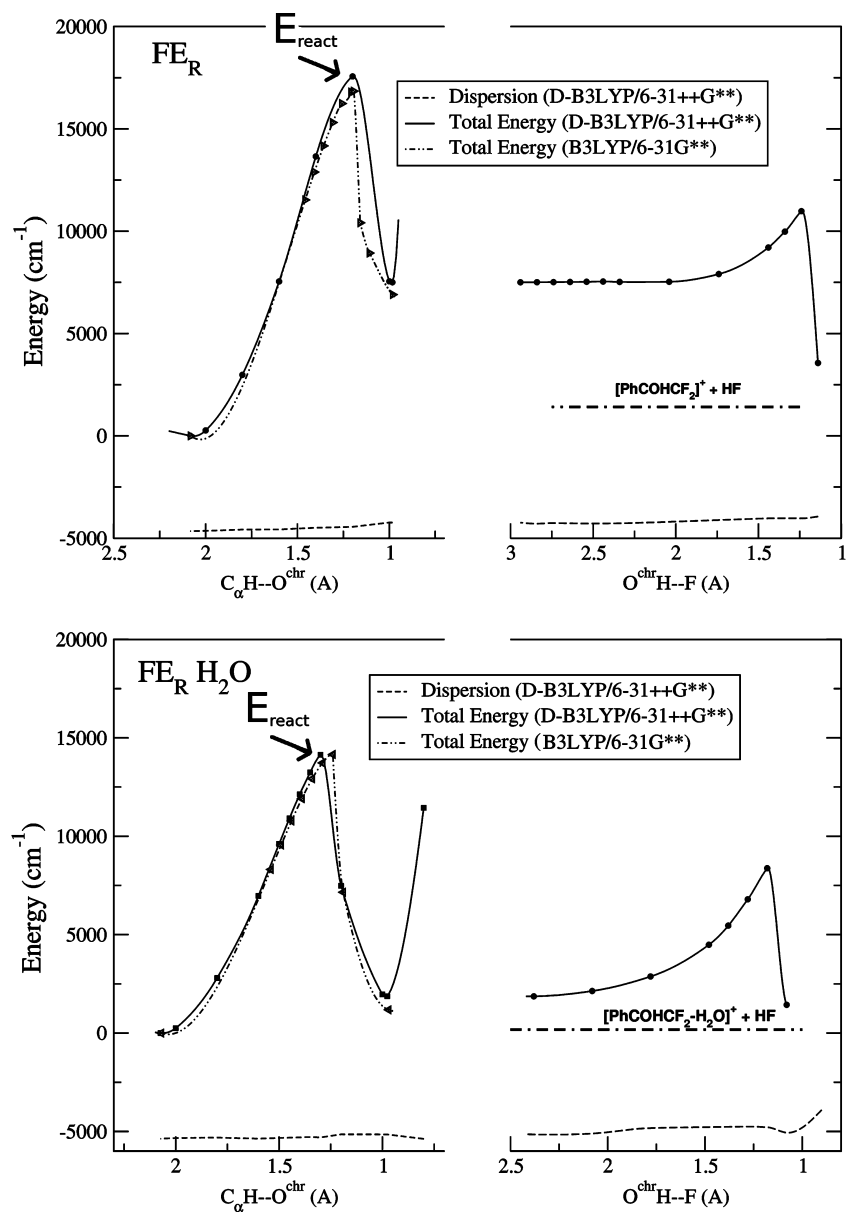

Figure 7. $\left[\mathbf{F E}_{\mathbf{R}}\right]^{+}$and $\left[\mathbf{F E}_{\mathbf{R}} \cdot \mathbf{W}\right]^{+}$: minimum energy paths for the transfer of $\mathrm{H}$ from $\mathrm{C}_{\alpha}$ to $\mathrm{O}^{\mathrm{chr}}$ (left sides) and for the transfer of $\mathrm{H}$ from $\mathrm{O}^{\text {chr }}$ to $\mathrm{F}$ (right sides). Different levels of DFT theory are compared. The dashed lines represent the dispersion total energy. The dashed-dashed-dotted lines represent the asymptotic energy of the fragments after the HF loss.
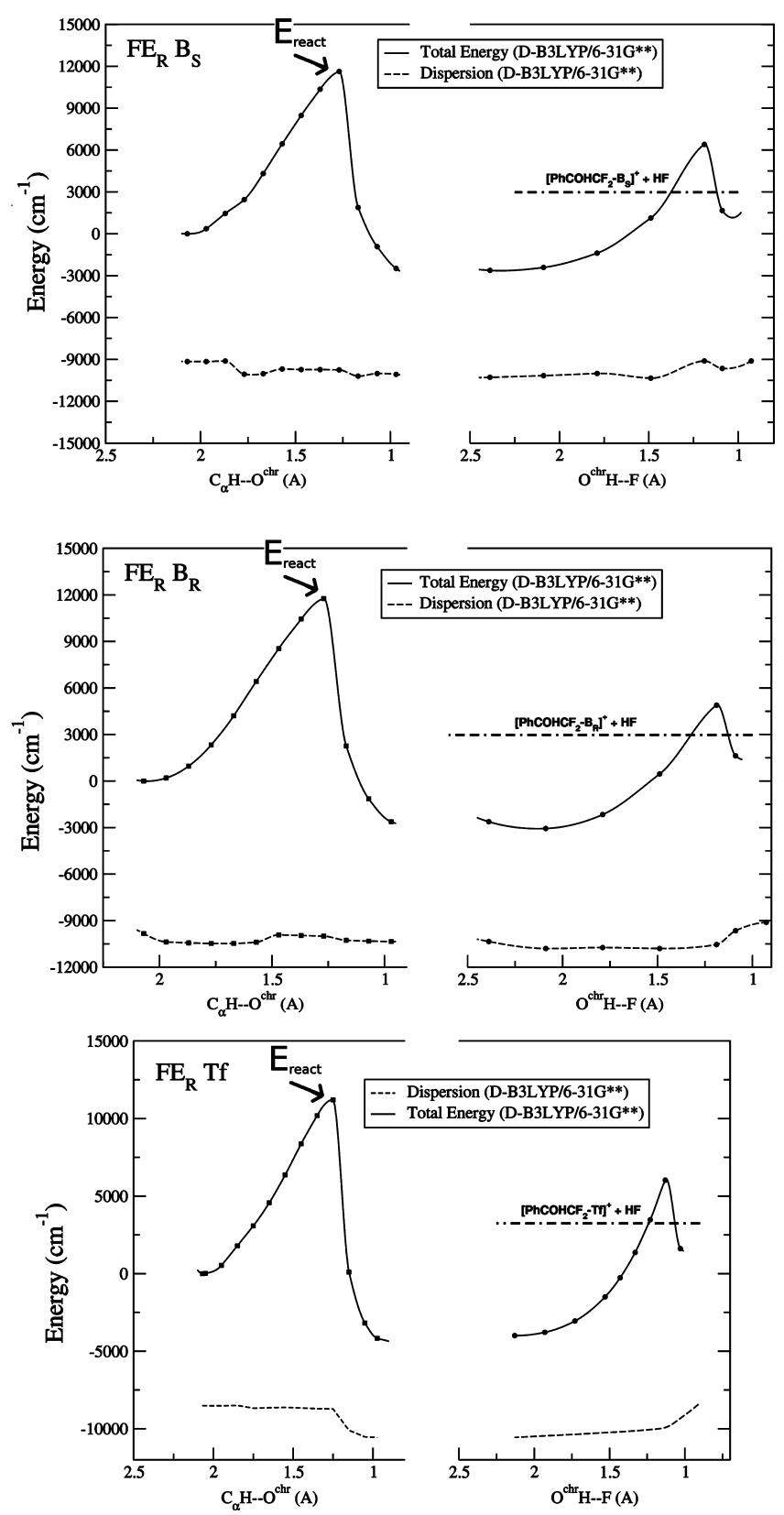

Figure 8. $\left[\mathbf{F E}_{\mathbf{R}} \cdot \mathbf{B}_{\mathbf{S}}\right]^{+},\left[\mathbf{F E}_{\mathbf{R}} \cdot \mathbf{B}_{\mathbf{R}}\right]^{+}$, and $\left[\mathbf{F E}_{\mathbf{R}} \cdot \mathbf{T f}\right]^{+}$: minimum energy paths for the transfer of $\mathrm{H}$ from $\mathrm{C}_{\alpha}$ to $\mathrm{O}^{\text {chr }}$ (left sides) and for the transfer of $\mathrm{H}$ from $\mathrm{O}^{\text {chr }}$ to $\mathrm{F}$ (right sides). Calculations at the Dispersion-B3LYP/ $6-31 \mathrm{G}^{* *}$ level of theory. The dashed lines represent the dispersion total energy. The dashed-dashed-dotted lines represent the asymptotic energy of the fragments after the HF loss.

conformers, rather than to vibronic transition of a single conformer. It is noted that the fragmentation ratios in the 1cR2PI-TOF mass spectra of the homochiral $\left[\mathbf{F E}_{\mathbf{R}} \cdot s o l v\right]($ solv $=\mathbf{B}_{\mathbf{R}}$ and $\left.\mathbf{T h}_{\mathbf{R}}\right)$ invariably exceed those of their heterochiral $\left[\mathbf{F E}_{\mathbf{R}} \cdot\right.$ solv $]\left(\right.$ solv $=\mathbf{B}_{\mathrm{S}}$ and $\left.\mathbf{T h}_{\mathrm{S}}\right)$ adducts.

The observation of extensive HF loss from $\left[\mathbf{F E}_{\mathbf{R}} \cdot \mathbf{T f}\right]^{+}$ suggests that the hydrogen involved is probably one of the $\mathrm{HO}-\mathrm{C}_{\alpha}-\mathrm{H}$ group of the chromophore. Besides, the absence of any detectable $\mathrm{HF}$ loss from the $\left[\mathbf{F P}_{\mathbf{R}} \cdot \boldsymbol{s o l} \boldsymbol{v}\right]^{+}$complexes $^{16}$ points to the $\mathrm{C}_{\alpha}-\mathrm{H}$ hydrogen of the chromophore as the one most likely involved in the HF elimination.

3.4. Mechanism of HF Elimination Reaction and Its Dependence on the Solvent. From the above, a comprehensive ab initio quantum chemical study has been undertaken to determine the reaction coordinate leading to HF loss from the 

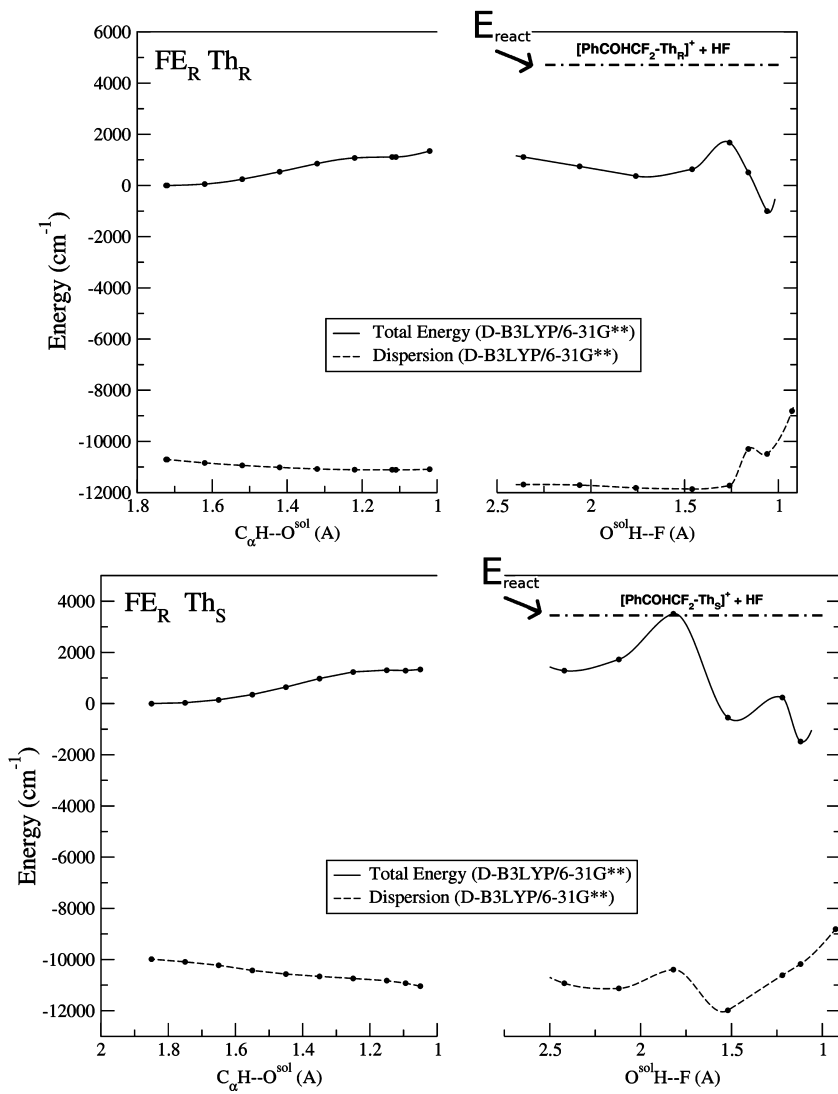

Figure 9. $\left[\mathbf{F E}_{\mathbf{R}} \cdot \mathbf{T h}_{\mathbf{R}}\right]^{+}$and $\left[\mathbf{F E}_{\mathbf{R}} \mathbf{T h}_{\mathbf{S}}\right]^{+}$: minimum energy paths for the transfer of $\mathrm{H}$ from $\mathrm{C}_{\alpha}$ to $\mathrm{O}^{\text {al }}$ (left sides) and for the transfer of $\mathrm{H}$ from $\mathrm{O}^{\text {al }}$ to $\mathrm{F}$ (right sides). Calculations at the Dispersion-B3LYP/6$31 \mathrm{G}^{* *}$ level of theory. The dashed lines represent the dispersion total energy. The dashed-dashed-dotted lines represent the asymptotic energy of the fragments after the HF loss.

ion clusters starting from the hypothesis that the hydrogen involved is the $\mathrm{C}_{\alpha}-\mathrm{H}$ one of the chromophore.

Three mechanisms have been considered most probable for the HF loss: (a) the direct $\mathrm{C}_{\alpha}-\mathrm{H}$ hydrogen transfer to the nearest fluorine atom of the $\mathrm{CF}_{3}$ group (a concerted process); (b) a preliminary hydrogen transfer from the $\mathrm{C}_{\alpha}$ to its vicinal oxygen of the chromophore $\left(\mathrm{O}^{\mathrm{chr}}\right)$ followed by the $\mathrm{H}$ transfer to the nearest fluorine atom of the $\mathrm{CF}_{3}$ group (an intramolecular twostep mechanism); (c) only for bidentate solvent $\mathbf{T h}_{\mathbf{R} / \mathbf{S}}$, a preliminary hydrogen transfer from the $\mathrm{C}_{\alpha}$ to the alcoholic oxygen $\left(\mathrm{H}-\mathrm{O}^{\text {al }}\right)$ of $\mathbf{T h}_{\mathbf{R} / \mathbf{S}}$ followed by the $\mathrm{H}$ transfer to the nearest fluorine atom of the $\mathrm{CF}_{3}$ group (an intermolecular mechanism).

Figures 7-9 illustrate the minimum energy paths for mechanisms b $\left(\right.$ solv $=$ none, $\mathbf{W}, \mathbf{B}_{\mathbf{R} / \mathbf{S}}$, and $\left.\mathbf{T f}\right)$ and $\mathrm{c}\left(\boldsymbol{s o l v}=\mathbf{T h}_{\mathbf{R} / \mathbf{S}}\right)$. All the energies are relative to that of the equilibrium geometry of the most stable $\left[\mathbf{F E}_{\mathbf{R}} \cdot \text { solv }\right]^{+}$ion. The $\mathrm{C}_{\alpha}$-to- $\mathrm{O}^{\text {chr/al }}$ hydrogen transfer step (left side of Figures 7-9) for each species was explored by a full optimization procedure in which the geometry is only constrained to fixed $\mathrm{O}^{\text {chr }}-\mathrm{H}$ or $\mathrm{O}^{\mathrm{al}}-\mathrm{H}$ distance. The optimized geometry of the intermediates produced in the first step is shown in Figure 10. The subsequent $\mathrm{O}^{\text {chr/al }}$-to-F hydrogen transfer step (right side of Figures 7-9) was explored by scanning the $\mathrm{H} \cdots \mathrm{F}$ distance. The dashed lines represent the total dispersive term contributions. The dashed-dotted line represents the energy of the final dissociation products, $\mathrm{HF}$ and $\mathrm{PhCOHCF}_{2}{ }^{+}$. In order to test the basis set size effect, the energy barriers for $\left[\mathbf{F E}_{\mathbf{R}}\right]^{+}$and $\left[\mathbf{F E}_{\mathbf{R}} \cdot \mathbf{W}\right]^{+}$were investigated at the D-DFT-B3LYP/6-31++G** level as well. The relevant energy

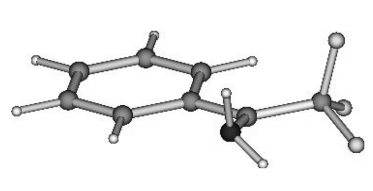

$\left[\mathrm{FE}_{\mathbf{R}}\right]^{+}$

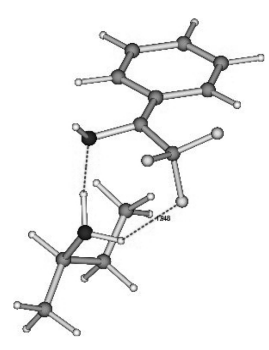

$\left[\mathrm{FE}_{\mathbf{R}} \cdot \mathbf{B}_{\mathbf{R}}\right]^{+}$

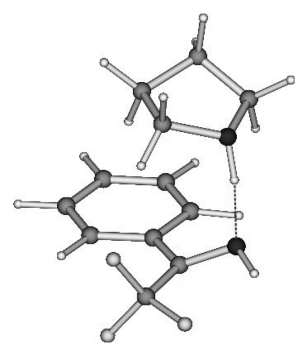

$\left[\mathrm{FE}_{\mathbf{R}} \cdot \mathbf{T f}\right]^{+}$

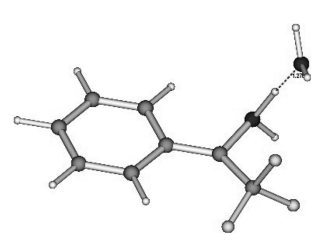

$\left[\mathbf{F E}_{\mathbf{R}} \cdot \mathbf{W}\right]^{+}$

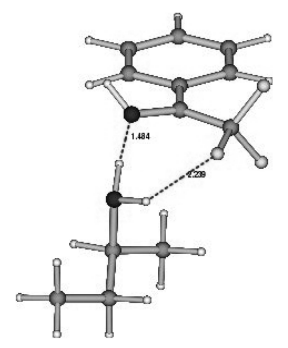

$\left[\mathrm{FE}_{\mathrm{R}} \cdot \mathbf{B}_{\mathrm{S}}\right]^{+}$

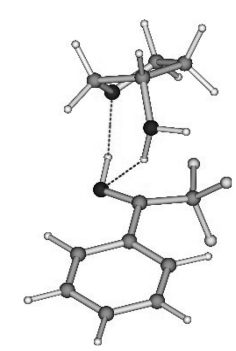

$\left[\mathbf{F E}_{\mathbf{R}} \cdot \mathbf{T h} \mathbf{h}_{\mathbf{R}}\right]^{+}$

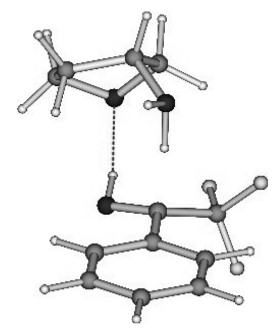

$\left[\mathrm{FE}_{\mathbf{R}} \cdot \mathbf{T h} \mathbf{h}_{\mathbf{S}}\right]^{+}$
Figure 10. D-B3LYP/6-31G** optimized geometry of intermediate states produced by $\mathrm{C}_{\alpha}$ to $\mathrm{O}^{\text {chr/solv }}$ hydrogen transfer.

profiles reveal no significant departures from those calculated at the DFT-B3LYP/6-31G** level (Figures 7). Table 2 reports the energetic data for the HF elimination process according to mechanisms b and c. The $E_{\text {react }}$ term refers to the minimum energy for the HF loss from the most stable $\left[\mathbf{F E}_{\mathbf{R}} \cdot \boldsymbol{s o l v}\right]^{+}$ion (indicated with arrows in Figure 7-9). $\Delta E^{\text {act }}$ is the sum of the adiabatic ionization potential of the species and $E_{\text {react }}\left(\Delta E_{\text {react }}\right.$ $\left.=\operatorname{IP}\left(\left[\mathbf{F E}_{\mathbf{R}} \cdot s o l v\right]\right)+E_{\text {react }}\right)$ and represents the overall HF loss activation barriers starting from the relevant neutral $\left[\mathbf{F E}_{\mathbf{R}} \cdot \boldsymbol{s o l v}\right]$ complexes. If the $E_{\text {react }}$ terms of Table 2 are compared to the larger B3LYP/6-31G**-calculated activation barriers, involved in the direct transfer mechanism a $\left(E_{\text {react }}=17960 \mathrm{~cm}^{-1}\right.$ for $\left[\mathbf{F E}_{\mathbf{R}}\right]^{+}, 15950 \mathrm{~cm}^{-1}$ for $\left[\mathbf{F E}_{\mathbf{R}} \cdot \mathbf{W}\right]^{+}, 15500 \mathrm{~cm}^{-1}$ for $\left[\mathbf{F E} \mathbf{E}_{\mathbf{R}} \cdot \mathbf{T f}\right]^{+}$, and $14700 \mathrm{~cm}^{-1}$ for $\left[\mathbf{F E}_{\mathbf{R}} \cdot \mathbf{T h}_{\mathbf{R}}\right]^{+}$), one is inclined to conclude that mechanisms $\mathrm{b}$ and $\mathrm{c}$ are those actually involved in the HF eliminations.

The analysis of the potential energy surfaces of $\left[\mathbf{F E} \mathbf{E}_{\mathbf{R}} \cdot \mathbf{B}_{\mathbf{R} / \mathbf{S}}\right]^{+}$ and $\left[\mathbf{F E}_{\mathbf{R}} \cdot \mathbf{T f}\right]^{+}$indicates that the $\mathrm{C}_{\alpha}$ to $\mathrm{O}^{\text {chr }}$ hydrogen transfer takes place in a concerted way with the hydrogen transfer from the $\mathrm{O}^{\text {chr }}-\mathrm{H}$ group to $\mathrm{O}^{\text {solv }}$. The optimized geometry of their transient intermediate states is shown in Figure 10. Their structure is characterized by the protonated $\mathbf{B}_{\mathbf{R} / \mathbf{S}}$ or $\mathbf{T f}$ molecules acting as proton donors toward $\mathrm{O}^{\mathrm{chr}}-\mathrm{H}$. In the case of $\left[\mathbf{F E}_{\mathbf{R}} \cdot \mathbf{T h}_{\mathbf{R} / \mathbf{S}}\right]^{+}$, the HF elimination reaction proceeds with a rather different mechanism. As reported in section 3.1, the most stable $\left[\mathbf{F E}_{\mathbf{R}} \cdot \mathbf{T h}_{\mathbf{R} / \mathbf{S}}\right]^{+}$adducts are characterized by a weak hydrogen bond between the $\mathrm{C}_{\alpha}-\mathrm{H}$ of $\mathbf{F E}_{\mathbf{R}}$ and the $\mathrm{O}^{\text {al }}$ atom of the solvent. According to Figure 9a,b (left side), the activation barriers for the hydrogen transfer from the $\mathrm{C}_{\alpha}-\mathrm{H}$ of $\mathbf{F E}_{\mathbf{R}}$ to $\mathrm{O}^{\mathrm{al}}$ are relatively small and the proton-transfer intermediate 
TABLE 2: Energetic Data for the HF Elimination Process in $\left[\mathrm{FE}_{\mathbf{R}}\right]^{+}$and $\left[\mathrm{FE}_{\mathbf{R}} \cdot \mathbf{s o l v}\right]^{+}$Clusters

\begin{tabular}{|c|c|c|c|c|c|c|}
\hline cluster & neutral structure & IP $\left(\mathrm{cm}^{-1}\right)$ & $E_{\text {react }}\left(\mathrm{cm}^{-1}\right)$ & $\Delta E_{\text {react }}\left(\mathrm{cm}^{-1}\right)$ & $2 h v(\exp )\left(\mathrm{cm}^{-1}\right)$ & $\Delta\left(\mathrm{cm}^{-1}\right)$ \\
\hline $\mathbf{F E}_{\mathrm{R}}$ & $\mathrm{A}$ & 72557 & 17563 & 90120 & 75564 & -14556 \\
\hline $\mathrm{FE}_{\mathrm{R}} \mathrm{H}_{2} \mathrm{O}$ & A & 70017 & 14135 & 84152 & 75584 & -8568 \\
\hline $\mathbf{F E}_{\mathrm{R}} \mathbf{B}_{\mathrm{R}}$ & $\mathrm{A}_{\text {homo }}$ & 67424 & 11768 & 79192 & 75452 & -3740 \\
\hline $\mathbf{F E}_{\mathrm{R}} \mathbf{B}_{\mathrm{S}}$ & $\mathrm{C}_{\text {hetero }}$ & 67588 & 11622 & 79210 & 75580 & -3630 \\
\hline $\mathrm{FE}_{\mathrm{R}} \mathrm{Tf}$ & A & 66924 & 11199 & 78123 & $75398-75468$ & -2655 to -2725 \\
\hline $\mathrm{FE}_{\mathrm{R}} T \mathrm{Th}_{\mathrm{R}}$ & $\mathrm{A}_{\text {homo }}$ & 65895 & 4714 & 70609 & $75374-75566$ & $4765-4957$ \\
\hline
\end{tabular}

(Figure 10) corresponds to a very shallow minimum on the relevant PES. It is then necessary to overcome other barriers to produce the subsequent adduct in which $\mathrm{HF}$ remains localized near the ionic cluster (Figure 9a,b; right side)). The $E_{\text {react }}$ term, in the reaction of $\left[\mathbf{F E} \mathbf{R}_{\mathbf{R}} \cdot \mathbf{T h}_{\mathbf{R} / \mathbf{S}}\right]^{+}$, refers to the dissociation pseudobarrier for the formation of the $\mathrm{HF}$ and $\left[\mathrm{PhCOHCF}_{2} \cdot \mathbf{T h}_{\mathbf{R}}\right]^{+}$. The value is different for the heteroand homoclusters because these complexes are still diastereomers formed by two chiral partners, namely, the solvent $\mathbf{T h}_{\mathbf{R} / \mathbf{S}}$ and $\left[\mathrm{PhCOHCF}_{2} \cdots \mathrm{HF}\right]^{+}$, which is not fully planar at $\mathrm{C}_{\alpha}$. The final products $\left[\mathrm{PhCOHCF}{ }_{2} \cdot \mathbf{T h}_{\mathbf{R} / \mathbf{S}}\right]^{+}$are not diastereomers anymore, but enantiomers.

Table 2 reports also the overall energy $\left(E_{2 h v}\right)$ imparted to the relevant neutral $\left[\mathbf{F E}_{\mathbf{R}} \cdot\right.$ solv $]$ complexes in the $1 \mathrm{cR} 2 \mathrm{PI}$ experiments. The difference $\Delta=E_{2 h v}-\Delta E_{\text {react }}$ represents the energy available to the ground state $\left[\mathbf{F E}_{\mathbf{R}} \cdot \boldsymbol{s o l v}\right]^{+}$after $\mathrm{HF}$ elimination. A negative $\Delta$ value indicates that the total energy furnished in the $1 \mathrm{cR} 2 \mathrm{PI}$ process is less than the calculated $\Delta E_{\text {react }}$ value. The largely negative $\Delta$ values, calculated for $\left[\mathbf{F E}_{\mathbf{R}} \cdot \boldsymbol{s o l v}\right]^{+}(\boldsymbol{s o l v}=$ none and $\mathbf{W}$ ), are consistent with the lack of any appreciable HF loss from the ion. The positive $\Delta$ values observed for $\left[\mathbf{F E}_{\mathbf{R}} \cdot \mathbf{T h}_{\mathbf{R} / \mathbf{S}}\right]^{+}$fully agree with the experimental findings of extensive HF elimination. Although the $\Delta$ values for $\left[\mathbf{F E}_{\mathbf{R}} \cdot \mathbf{B}_{\mathbf{R}}\right.$ $\mathbf{s}]^{+}$and $\left[\mathbf{F E}_{\mathbf{R}} \cdot \mathbf{T f}\right]^{+}$are negative, the experimental increasing extent of HF loss in going from $\left[\mathbf{F E}_{\mathbf{R}} \cdot \mathbf{B}_{\mathbf{R} / \mathbf{S}}\right]^{+}$to $\left[\mathbf{F E}_{\mathbf{R}} \cdot \mathbf{T f}\right]^{+}$ seems to parallel the values of their $\Delta$ energy gap, which are less negative in the case of $\left[\mathbf{F E}_{\mathbf{R}} \cdot \mathbf{T f}\right]^{+}$.

A possible interpretation of the disagreement between the extensive $\mathrm{HF}$ elimination observed in $\left[\mathbf{F E}_{\mathbf{R}} \cdot \mathbf{B}_{\mathbf{R} / \mathbf{S}}\right]^{+}$and $\left[\mathbf{F E}_{\mathbf{R}} \cdot \mathbf{T f}\right]^{+}$(Table 1) and their negative $\Delta$ values is based on the hypothesis of hydrogen tunneling across the first barrier. This could be the case when the vibrational kinetic energy of the hydrogen is high enough to be just below the maximum height of the barrier itself. Another question concerns the enantioselective $\mathrm{HF}$ elimination reaction observed in the ionic

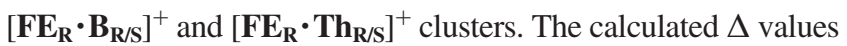
for the homochiral and heterochiral adducts do not seem to agree with the experimental findings. As can be seen from Figures 8 and 9, the activation energies involved in the various reaction steps differ for the homo- and heteroadducts. In particular, the transfer of the hydrogen atom to the nearest fluorine atom is more kinetically favored in the $\left[\mathbf{F E}_{\mathbf{R}} \cdot \mathbf{B}_{\mathbf{R}}\right]^{+}$and $\left[\mathbf{F E}_{\mathbf{R}} \cdot \mathbf{T h}_{\mathbf{R}}\right]^{+}$ homochiral complexes, and this could explain the observed higher fragmentation ratios.

\section{Conclusions}

The present paper reports on the investigation of the mechanism of enantioselective Hf loss reaction in isolated ionic complexes by a combined experimental theoretical study. Mass selected resonant two photon ionization (R2PI-TOF) is used to record the $\mathrm{S}_{1} \leftarrow \mathrm{S}_{0}$ spectra of $(R)$-1-phenyl-2,2,2-trifluoroethanol $\left(\mathbf{F E}_{\mathbf{R}}\right)$ and its hydrogen bonded adducts with water $(\mathbf{W})$ and tetrahydrofuran (Tf) and chiral solvent molecules $((R)$ - and $(S)$ - butan-2-ol ( $\left.\mathbf{B}_{\mathbf{R} / \mathbf{S}}\right)$, and $(R)$ - and $(S)$-3-hydroxy-tetrahydrofuran $\left.\left(\mathbf{T h}_{\mathbf{R} / \mathbf{S}}\right)\right)$. The structure of their neutral and ionic adducts has been analyzed on the basis of theoretical predictions at the B3LYP/6-31G** level of theory with the inclusion of dispersive terms.

The parent radical ions formed by R2PI of the $\left[\mathbf{F E}_{\mathbf{R}} \cdot \boldsymbol{s o l v}\right]$ adducts (solv $=\mathbf{T f}, \mathbf{B}_{\mathbf{R} / \mathbf{S}}, \mathbf{T h}_{\mathbf{R} / \mathbf{S}}$ ) produce fragments attributable to the occurrence of an hydrogen fluoride loss reaction. Three possible mechanisms have been investigated by quantum chemical calculations at the DFT level of theory with the inclusion of dispersive terms. For $\left[\mathbf{F E}_{\mathbf{R}} \cdot \mathbf{B}_{\mathbf{R} / \mathbf{S}}\right]^{+}$and $\left[\mathbf{F E} \mathbf{E}_{\mathbf{R}} \cdot \mathbf{T f}\right]^{+}$ clusters, the HF elimination process takes place by a two-step intramolecular mechanism involving a preliminary hydrogen transfer from the $\mathrm{C}_{\alpha}$ to its vicinal oxygen $\left(\mathrm{O}^{\text {chr }}\right)$ with concerted hydrogen transfer from $\mathrm{O}^{\text {chr }}$ to $\mathrm{O}^{\text {solv }}$. The second step involves the $\mathrm{H}$ transfer from $\mathrm{O}^{\text {chr }}$ to the nearest fluorine atom of the $\mathrm{CF}_{3}$ group. For $\left[\mathbf{F E}_{\mathbf{R}} \cdot \mathbf{T h}_{\mathbf{R} / \mathbf{s}}\right]^{+}$complexes the HF loss process involves a preliminary hydrogen transfer from $\mathrm{C}_{\alpha}$ to the alcoholic oxygen $\left(\mathrm{H}-\mathrm{O}^{\text {al }}\right)$ of $\mathbf{T h}_{\mathbf{R} / \mathbf{S}}$ followed by the $\mathrm{H}$ transfer to the nearest fluorine atom of the $\mathrm{CF}_{3}$ group.

The calculations predict a lowering of the energy barriers or pseudobarriers for the HF loss process in the order $\left[\mathbf{F E}_{\mathbf{R}} \cdot \mathbf{W}\right]^{+}$ $>\left[\mathbf{F E}_{\mathbf{R}} \cdot \mathbf{B}_{\mathbf{R} / \mathbf{S}}\right]^{+}>\left[\mathbf{F E}_{\mathbf{R}} \cdot \mathbf{T f}\right]^{+}>\left[\mathbf{F E}_{\mathbf{R}} \cdot \mathbf{T h}_{\mathbf{R} / \mathbf{S}}\right]^{+}$in fair agreement with the increase of the corresponding photofragmentation ratios. The lower values of the pseudobarriers calculated for $\left[\mathbf{F E}_{\mathbf{R}} \cdot \mathbf{T h}_{\mathbf{R} /}\right.$ $\mathrm{s}^{+}$are consistent with the observed extensive HF elimination. In the case of $\left[\mathbf{F E}_{\mathbf{R}}\right]^{+},\left[\mathbf{F E}_{\mathbf{R}} \cdot \mathbf{W}\right]^{+},\left[\mathbf{F E}_{\mathbf{R}} \cdot \mathbf{B}_{\mathbf{R} / \mathbf{S}}\right]^{+}$, and $\left[\mathbf{F E}_{\mathbf{R}} \cdot \mathbf{T f}\right]^{+}$, the overall energy imparted in the 1cR2PI is lower than the calculated overall HF loss activation barriers starting from the neutral. This is in agreement with the lack of any appreciable $\mathrm{HF}$ loss from $\left[\mathbf{F E}_{\mathbf{R}}\right]^{+}$and $\left[\mathbf{F E}_{\mathbf{R}} \cdot \mathbf{W}\right]^{+}$. The extensive $\mathrm{HF}$ elimination observed in $\left[\mathbf{F E}_{\mathbf{R}} \cdot \mathbf{B}_{\mathbf{R} / \mathbf{S}}\right]^{+}$and $\left[\mathbf{F E}_{\mathbf{R}} \cdot \mathbf{T f}\right]^{+}$has been explained by the hypothesis of hydrogen tunneling across the first energy barrier.

The efficiency of the HF loss fragmentation process in the

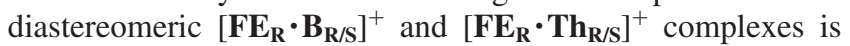
higher for the homochiral complexes than for the heterochiral adducts. The phenomenological enantioselectivity could be due to a kinetically more favored $\mathrm{O}^{\text {solv }}-\mathrm{H}$ to $\mathrm{F}$ transfer in the homochiral adducts.

Acknowledgment. Contract grant sponsor, Ministero dell'Università e della Ricerca (MIUR-PRIN) and Consiglio Nazionale delle Ricerche (CNR).

\section{References and Notes}

(1) Al Rabaa, A. R.; Bréhéret, E.; Lahmani, F.; Zehnacker, A. Chem. Phys. Lett. 1995, 237, 480.

(2) Piccirillo, S.; Bosman, C.; Giardini, A.; Pierini, M.; Troiani, A.; Speranza, M. Angew. Chem., Int. Ed. Engl. 1997, 36, 1729.

(3) Borho, N.; Suhm, M. Phys. Chem. Chem. Phys. 2002, 4, 2721.

(4) (a) King, A. K. J. Chem. Phys. Lett. 2001, 348, 343. (b) Su, Z.; Borho, N.; Xu, Y. J. Am. Chem. Soc. 2006, 128, 17126.

(5) Latini, A.; Satta, M.; Giardini Guidoni, A.; Piccirillo, S.; Speranza, M. Chem.-Eur. J. 2000, 6, 1042. 
(6) Speranza, M.; Rondino, F.; Satta, M.; Paladini, A.; Giardini, A.; Catone, D.; Piccirillo, S. Chirality 2009, 21, 119.

(7) Catone, D.; Paladini, A.; Piccirillo, S.; Rondino, F.; Satta, M.; Scuderi, D.; Scuderi, D.; Speranza, M. Angew. Chem., Int. Ed. 2004, 43 (14), 1868.

(8) (a) Giardini-Guidoni, A.; Piccirillo, S.; Sscuderi, D.; Satta, M.; Di Palma, T. M.; Speranza, M.; Fillippi, A.; Paladini, A. Chirality 2001, 730, 13727. (b) Giardini-Guidoni, A.; Piccirillo, S. Isr. J. Chem. 1997, 37, 439.

(9) Piccirillo, S.; Coreno, M.; Giardini-Guidoni, A.; Pizzela, G.; Snels, M.; Teghil, R. J. Mol. Struct. 1993, 293, 197.

(10) (a) Schwabe, T.; Grimme, S. Phys. Chem. Chem. Phys. 2007, 9, 3397. (b) Jureka, P.; Cerny, J.; Hobza, P.; Salahub, D. R. J. Comput. Chem. 2007, 28 (2), 555 .

(11) Grimme, S.; Antony, J.; Schwabe, T.; Muck-Lichtenfeld, C. Org. Biomol. Chem. 2007, 5, 741.

(12) Grimme, S. J. Comput. Chem. 2006, 27, 1787.

(13) Frisch, M. J.; Trucks, G. W.; Schlegel, H. B.; Scuseria, G. E.; Robb, M. A.; Cheeseman, J. R.; Zakrzewski, V. G.; Montgomery, J. A., Jr.; et al. Gaussian 98, Revision A.6; Gaussian, Inc.: Pittsburgh, PA, 1998.

(14) Straatsma, T. P.; Aprà, E.; Windus, T. L.; Bylaska, E. J.; de Jong, W.; Hirata, S.; Valiev, M.; Hackler, M.; Pollack, L.; Harrison, R.; Dupuis, M.; Smith, D. M. A.; Nieplocha, J. V.; Tipparaju, V.; Krishnan, M.; Auer, A. A.; Brown, E.; Cisneros, G.; Fann, G.; Früchtl, H.; Garza, J.; Hirao, K.;
Kendall, R.; Nichols, J.; Tsemekhman, K.; Wolinski, K.; Anchell, J.; Bernholdt, D.; Borowski, P.; Clark, T.; Clerc, D.; Dachsel, H.; Deegan, M.; Dyall, K.; Elwood, D.; Glendening, E.; Gutowski, M.; Hess, A.; Jaffe, J.; Johnson, B.; Ju, J.; Kobayashi, R.; Kutteh, R.; Lin, Z.; Littlefield, R.; Long, X.; Meng, B.; Nakajima, T.; Niu, S.; Rosing, M.; Sandrone, G.; Stave, M.; Taylor, H.; Thomas, G.; van Lenthe, J.; Wong, A.; Zhang, Z. NWChem, A Computational Chemistry Package for Parallel Computers, Version 4.6; Pacific Northwest National Laboratory: Richland, WA, 2004. Kendall, R. A.; Aprà, E.; Bernholdt, D. E.; Bylaska, E. J.; Dupuis, M.; Fann, G. I.; Harrison, R. J.; Ju, J.; Nichols, J. A.; Nieplocha, J.; Straatsma, T. P.; Windus, T. L.; Wong, A. T. High performance Computational Chemistry: an Overview of NWChem a Distributed Parallel Application. Comput. Phys. Commun. 2000, $128,260$.

(15) Giardini, A.; Rondino, F.; Cattenacci, G.; Paladini, A.; Piccirillo, S.; Satta, M.; Speranza, M. Chem. Phys. Lett. 2007, 435, 230.

(16) Giardini, A.; Rondino, F.; Paladini, A.; Hortal, A. R.; Satta, M.; Speranza, M.; Piccirillo, S. Phys. Scr. 2008, 78, 058121.

(17) Piccirillo, S.; Rondino, F.; Catone, D.; Giardini Guidoni, A.; Paladini, A.; Tacconi, M.; Satta, M.; Speranza, M. J. Phys. Chem. A 2005, 109 (9), 1828.

JP905322N 